\section{LA PRODUCCIÓN PERIODÍSTICA DEL EXILIO REPUBLICANO (1939-1950)*}

\author{
Matilde Eiroa San Francisco \\ Departamento de Periodismo y Comunicación Audiovisual \\ Universidad Carlos III de Madrid \\ meiroa@hum.uc3m.es
}

Cómo citar este artículo/ Citation: Eiroa San Francisco, M. (2013). La producción periodística del exilio republicano (19391950). Arbor, 189(759):a010. doi: http://dx.doi.org/10.3989/ arbor.2013.759n1009

Recibido: 14 junio 2010; Aceptado: 20 septiembre 2011.

RESUMEN: El artículo tiene como objetivo analizar la tipología y características de los medios de comunicación del exilio republicano durante su etapa más fructífera correspondiente al decenio 1939-1950. Se han utilizado los fondos del Archivo de la República Española en el Exilio, el Partido Comunista de España, la Fundación Pablo Iglesias y el Centro de Investigación para la República Española en el Exilio (CIERE) a los que se ha aplicado la metodología cualitativa y el enfoque deductivo como vías de acercamiento a la realidad socio-comunicativa objeto del estudio.

Partimos de la idea de que el perfil de los protagonistas de dichos medios y su disgregación en Europa y América influyeron en la segmentación e inestabilidad de las publicaciones. A lo largo de sus páginas se localizan los focos principales de la producción periodística exiliada y se examinan a grandes rasgos los prototipos, los contenidos y los actores.

PALABRAS CLAVE: Prensa exiliada; periodismo exiliado; exilio republicano; exilio en México; exilio en Francia.

\section{THE JOURNALISTIC PRODUCTION OF THE SPANISH REPUBLICAN EXILE (1939-1950)}

Copyright: (C) 2013 CSIC. Este es un artículo de acceso abierto distribuido bajo los términos de la licencia Creative Commons Attribution-Non Commercial (by-nc) Spain 3.0.

ABSTRACT: The aim of this article is to analyse the typology and characteristics of the Spanish Republican exile media during its most productive stage (1939-1950). The funds of the Spanish Republic Archive in Exile, the Communist Party of Spain, the Pablo Iglesias Foundation and the Research Centre for the Spanish Republic in Exile (CIERE) have been used in this research. We have used qualitative techniques and a deductive approach as ways of dealing with the object of study. Our starting point is the idea that the profile of the editors and journalists and their dispersal across Europe and America contributed to the fragmentation and fragility of its publications. The main centres of journalistic output in exile are set out, and we examine prototypes, contents and actors.

KEYWORDS: Press exiled; exiled journalism; Spanish Republican exile; Spanish exile in Mexico; Spanish exile in France.

*Este trabajo se enmarca en el proyecto de investigación dirigido por Consuelo Naranjo cuya referencia es: HAR2012-37455-C03-01 (MINECO)

El exilio de los republicanos fieles a la II República cuenta ya con un importante volumen de estudios (Abellán, 1982; Alted, 2006; Egido, 2006; Egido y Eiroa, 2004; Lemús, 2002 o Naranjo Orovio, 2009) que ha puesto de relieve la magnitud del fenómeno. En los últimos años los historiadores, animados por el movimiento social a favor de la recuperación de la memoria, han publicado investigaciones que van satisfaciendo esta demanda del presente, aunque quedan ámbitos que todavía necesitan ser rescatados de los archivos y recuperados para la sociedad del futuro. Uno de ellos es el sector informativo en su calidad de órgano de expresión social, configurado como uno de los importantes protagonistas de la época. En la ac- 
tualidad contamos con los estudios presentados en los congresos sobre creación literaria y periodística organizados por GEXEL-AEMIC o la Asociación de Historiadores de la Comunicación, y las monografías sobre sus actores o las cabeceras, como las de P. L. Angosto, L. Díez, L. Zaragoza, A. González Neira, J. C. Sánchez Illán o R. Surroca entre otros. Incluso conocemos el perfil biográfico de más de 300 redactores, fotógrafos, cronistas, corresponsales y el resto de las profesiones implicadas en el proceso informativo (Sánchez Illán, 2011). Todos conforman un catálogo pionero y novedoso de gran valía pero muy escaso numéricamente que urge ser extendido a la distinta tipología informativa trasladada al exilio a raíz de la victoria del ejército franquista en la Guerra Civil.

\section{LOS CENTROS DE LA PRODUCCIÓN INFORMATIVA, DESTI- NOS OBLIGADOS PARA LOS EXILIADOS}

La historiografía ha desvelado suficientemente cómo la salida de españoles fieles a la legalidad constitucional fue constante desde septiembre de 1936, por lo que el término aceptado de "exilio de 1939" responde más a una denominación sintética de este fenómeno que a la precisión del mismo.

La dispersión fue la nota predominante de los transterrados, exceptuando los dos grandes núcleos que se concentraron en Francia y México. La vida no fue fácil durante el tiempo que duró la II Guerra Mundial con la amenaza constante de las tropas de ocupación alemanas, situación que les obligaba a vivir escondidos y a cambiar de residencia con más asiduidad de lo deseado. Muchos fueron conducidos a campos de concentración y, en general, tropezaron con distintas vicisitudes dependiendo del país donde hicieron la primera parada de su destino incierto. Los pocos que lograron visado para Gran Bretaña ${ }^{1}$ (Arasa, 1995) y Suiza gozaron de cierta estabilidad, pero la mayoría partió para Iberoamérica y, en menor medida, Estados Unidos (Naranjo Orovio, 2009). En este continente corrieron mejor suerte, especialmente los que se asentaron en el México de Lázaro Cárdenas. Pero también hubo españoles de distinto perfil en Argentina, Chile, Cuba, Venezuela o en la República Dominicana, países en los que su fortuna dependió de la tendencia política y de la situación económica de sus gobiernos (Schwarzstein, 2001; Carcedo, 2006).

La distribución por los distintos territorios tuvo relación, entre otras circunstancias, con su adscripción política e ideológica. Los partidos socialistas y los comunistas se asentaron sobre todo en Francia y éstos últimos lo hicieron también en los países del bloque soviético. Los grupos de republicanos de izquierda se ubicaron en Francia, México y América del Sur. El gobierno republicano en el exilio experimentó, asimismo, cambios de sede: en un principio se apostó en México, pero posteriormente pasó a París por la hipótesis de un retorno inmediato a tierras españolas (Cabeza Sánchez-Albornoz, 1997). Otros grupos se establecieron en destinos infrecuentes dando lugar a una disgregación que impedía diseñar una estrategia política común, factor que unido a las persistentes divergencias políticas, la II Guerra Mundial, la Guerra Fría, la falta de apoyos internacionales y la disminución de recursos económicos, conforman un conjunto de argumentos que bien podrían explicar la falta de alternativa al franquismo.

Esta localización del éxodo tuvo, sin lugar a dudas, su reflejo en los medios de comunicación republicanos. Acostumbrados a ese impulso recibido desde los tiempos de la Constitución de 1931 con la aprobación de la libertad de imprenta, no cejaron en su empeño de continuar informando desde planteamientos políticos, propagandísticos, culturales o de cohesión social. No en vano heredaban esa tendencia inaugurada en los años republicanos, una de las etapas más brillantes y prolífica de la historia del periodismo español -la Edad de Oro, según denominación de algunos autores-, en la que se había propiciado la puesta en marcha de multitud de medios de comunicación con propósitos dispares.

El mundo de la información en el exilio quedó, pues, completamente descabalado ante las anómalas circunstancias de sus actores, pendientes de reorganizar sus vidas y sus haciendas y atentos a los acontecimientos políticos en España. La producción mediática en estas condiciones se hizo especialmente complicada, aunque desde el mismo momento de la salida crearon y distribuyeron sencillas publicaciones que respondían a un deseo intencionado de comunicación y de expresión de los recién expulsados (Sánchez Vázquez, 1989) $)^{2}$. Tanto en estos años como en posteriores las dificultades para la publicación de los distintos rotativos constituyen por sí mismas un capítulo especial de nuestra historia reciente. Además de los problemas derivados de la falta de recursos económicos, hemos de tener en cuenta las trabas que algunos gobiernos pusieron a la existencia de medios de comunicación republicanos así como los obstáculos tecnológicos que conllevaba no disponer de maquinaria propia o la escasez de periodistas profesionales, colectivo muy castigado en el proceso represivo desencadenado en España. La distribución de los impresos era arriesgada y de una extremada lentitud debido a la limitación de los transportes en tiempos de Guerra Mundial y la posterior restricción de las comunicaciones en los años de división del mundo en bloques.

Las principales cabeceras republicanas se editaron, organizándolas por continentes (Piedrafita, 1996): en África: Argelia - prensa socialista, comunista y de republicanos de izquierda- y Marruecos. En América 
del Sur: Argentina, Brasil, Colombia, Chile, Uruguay y Venezuela. La mayoría se publicó desde Argentina, especialmente prensa gallega, asturiana, catalana y vasca. En América Central y Caribe destacó Cuba, aunque algunas publicaciones se editaron en Costa Rica, Guatemala y Puerto Rico. En el Norte del continente sobresalió México, principal receptor de los refugiados, país desde el que se expresaron todos los órganos de partidos políticos, sindicatos y asociaciones de republicanos, así como las instituciones de la II República en el exilio. En Estados Unidos, los exiliados contaron con el apoyo de las Sociedades Hispanas Confederadas mientras que en Europa hemos de destacar el núcleo de Francia - París, Toulouse y en menor medida Perpiñán-, lugar fundamental en la producción informativa exiliada ${ }^{3}$. En este caso se encontraron con problemas idiomáticos que les supusieron importantes trabas para su trabajo en las redacciones, aunque con el paso del tiempo algunos montaron empresas editoriales como Ruedo Ibérico, fundada en París por José Martínez en 1960 (Forment, 2000).

Francia y México, pues, se configuran como los principales centros editores, seguidos muy de lejos por Argentina, Chile, República Dominicana, Cuba, Argelia y Venezuela (Sánchez Illán, 2005), dibujando un mapa coincidente con los destinos de la diáspora. Las cabeceras republicanas, por tanto, fueron capaces de salvar obstáculos de gran complejidad para llegar a su público objetivo y cumplir con la función común de lucha antifranquista e identidad republicana que tenían asumida como intrínseca a los propios medios.

\section{LA TIPOLOGÍA PERIODÍSTICA: POLÍTICA, CULTURA E INSTI- TUCIONES EN EL PANORAMA MEDIÁTICO}

La categorización informativa del republicanismo en el exilio responde fundamentalmente al periodismo especializado. En primer lugar, se puede distinguir la prensa política - partidista y sindical-, la tendencia más prolífica y de mayor duración en relación con una sociedad fragmentada ideológicamente y muy politizada. En segundo lugar los medios editados desde los ateneos, centros culturales y asociaciones, en consonancia con el alto nivel cultural del exilio; y finalmente la comunicación institucional, divulgada desde el gobierno de la República. Los tres tipos de publicaciones estuvieron sometidos a las coyunturas económicas de cada centro emisor pero también a oscilaciones políticas y a cambios de residencia de los exiliados, factores que influyeron en la periodicidad y la durabilidad.

En cuanto a la prensa política, hemos de destacar el hecho de que los órganos pertenecientes al PSOE, PCE, Izquierda Republicana y CNT constituyen el grupo más estable y de mayor continuidad comparado con el resto de medios. Sus objetivos, en general, conjugaban la denuncia del franquismo con la propaganda partidista y funcionaban como arma política y de difusión ideológica. No tenían afán de lucro y estaban financiados por las cuotas de los afiliados y las suscripciones de lectores, unos ingresos que apenas cubrían los gastos. EI PSOE disponía de El Socialista, con periodicidad mensual y ediciones en Toulouse, París, México, Argel. En sus secciones justificaba los ideales del socialismo planteados en la Segunda Internacional, defendía la vigencia del sistema democrático y promovía la solidaridad del movimiento obrero internacional en la lucha contra el franquismo ${ }^{4}$. En México los socialistas publicaban Adelante - con comentarios y colaboraciones de los residentes, especialmente de Indalecio Prieto, principal inspirador del mismo- y también Renovación, órgano de las Juventudes Socialistas, seguidor de la corriente prietista dentro del PSOE.

El PCE contaba fundamentalmente con Mundo Obrero, editado en París, Toulouse y Argel. Asimismo España Popular y Nuestra Bandera, centradas en la lucha antifranquista, y configuradas como punto de encuentro entre los comunistas disgregados por Europa. Ambos órganos llegaban hasta los residentes en los países del Este a pesar de las dificultades de transporte existentes desde París hasta Sofía o Bucarest ${ }^{5}$. Un canal de comunicación de especial importancia fue Radio España Independiente, estación Pirenai$c a$, nacida a iniciativa de la KOMINTERM en julio de 1941, un mes después de la agresión nazi a la URSS y el mismo mes que Ramón Serrano Suñer enviaba la División Azul al frente ruso. En Moscú se hallaban los principales dirigentes comunistas europeos $y$, en consecuencia, era el lugar idóneo para organizar las emisoras nacionales que se encargarían desde 1941 de la propaganda antifascista. Radio Pirenaica, como fue rebautizada, tuvo su sede en la URSS hasta enero de 1955 , fecha en que se trasladó a Bucarest porque el gobierno soviético se orientó hacia un cambio en sus relaciones con España y deseaba salvar el impedimento que podría representar la existencia de Pirenaica en su territorio (Mendezona, 1995; Millán Trujillo, 1998; Zaragoza, 2007 y 2008, Eiroa, 2011). Junto a esta radio, en las capitales del Este europeo se instalaron algunas emisoras en las que trabajaban comunistas españoles y salían al aire en lengua española. Este era el caso de Radio Varsovia ${ }^{6}$ o Radio Bucarest ${ }^{7}$, estaciones de muy menguados recursos pero de gran validez para el PCE.

El partido Izquierda Republicana contaba con órganos propios y otros afines cuyos cometidos eran comunes: la denuncia del franquismo y la reivindicación de la legalidad republicana. Un ejemplo fue Izquierda Republicana, publicado en México a partir de 1944 y de periodicidad mensual que intentó mantener vivo el recuerdo de Azaña y su ideario ${ }^{8}$. También en este país disponían de República Española, órgano de la facción disidente de Izquierda Republicana encabezada 
por Mariano Ruiz Funes, partidaria de la colaboración con Negrín y el PCE. El Ateneo Republicano Español era el responsable de Nuestra República, publicada igualmente en México ${ }^{9}$. En Argentina este grupo editó hasta 1974 el semanario España Republicana donde colaboraban Indalecio Prieto, Carlos Esplá, Giner de los Ríos, Félix Gordón Ordás o Diego Martínez Barrio. Hubo otras publicaciones políticas y algunas que, sin pertenecer a ninguna filiación concreta, decidieron organizarse como medio de expresión de liberales y republicanos en general con propósitos de cohesión y de mediación política ante la persistencia del franquismo en el poder. Es el caso, entre otros, de L'Espagne Républicaine, editada en Toulouse desde 1945 a 1949 por el político y periodista Ricardo Gasset Alzugaray (Bahamonde y Sánchez Illán, 2008 y 2010). Esta prestigiosa cabecera combinaba el periodismo político y el cultural y en sus páginas se puede constatar el lamento por las discrepancias en el exilio.

En segundo lugar se encuentran los numerosos centros culturales e instituciones que editaron sus propios medios de comunicación. Los republicanos refugiados en la embajada de Chile nada más finalizar la guerra redactaron Luna, considerada la primera revista cultural a la que seguirían muchas más. A esta misma categoría responde España Libre, órgano de las Sociedades Hispánicas Confederadas de los Estados Unidos de América publicado mensualmente en Nueva York, en cuyas páginas se expresó el colectivo de profesionales universitarios de distintas disciplinas humanísticas y científicas ${ }^{10}$. También en Ibérica -1953-1974, revista fundada y dirigida por Victoria Kent-, confluyeron personas desde ámbitos diversos, especialmente republicanos liberales como Salvador de Madariaga. Fue cauce de expresión de la oposición interna y puente de unión entre el exilio interior y exterior.

Los centros y asociaciones de emigrados promovieron revistas culturales y boletines de gran calidad que despertaban un gran interés entre sus lectores, especialmente porque contenían una información dirigida a un público de perfil muy específico. Entre las más conocidas figuran Nuestra España - la primera revista fundada en Cuba por el exilio-, Espuela de Plata, Romance, Hora de España, España Peregrina, Las Españas o Litoral, en memoria de la revista malagueña que desempeñó un papel crucial en la poesía de la década de los veinte y treinta (Gutiérrez Palacio, 2009).

Gallegos, catalanes y vascos, pero también colectivos profesionales o mujeres dispusieron de impresos con formatos variados y expresivos de la voluntad de servir de canal eficaz de comunicación al republicanismo. Algunos ejemplos los encontramos en Boletín de la Unión de Intelectuales Españoles, Boletín de Unión de Mujeres Españolas, Unión de Profesores Universitarios Españoles en el Extranjero, Galicia, Catalunya,
Boletín del Instituto Americano de Estudios Vascos o la revista Vamos, fundada y dirigida en 1939 por la periodista canaria Mercedes Pinto (Domínguez Prats, 1988).

En Argentina los exiliados fundaron la editorial Espasa Calpe, Losada (donde editaban a Lorca, Alberti, Ayala, Rosa Chacel, María Zambrano o Sánchez-Albornoz), Emecé, Pleamar, Editorial Sudamericana y Nuevo Romance. En Chile se hallaba la Editorial Cruz del Sur y en México las empresas editoriales e informativas componen un catálogo importante entre las industrias culturales. En este país el antiguo director de periódicos Roberto Castrovido fundó la librería Góngora poco antes de su fallecimiento. No en vano se puede afirmar que México se erigió en la capital de la prensa literaria del exilio durante la década de 1940 y 1950 hasta que las circunstancias políticas y el paso del tiempo provocarán su declive.

En tercer lugar figuran los medios de comunicación institucionales, subordinados a los vaivenes políticos del gobierno exiliado y al reducido soporte económico. Frente a la España de Franco organizada con una estructura informativa fortalecida progresivamente con recursos humanos y económicos, el ejecutivo republicano careció de un sistema mediático eficaz y reducido al mínimo con motivo de la paulatina y drástica disminución de las arcas gubernamentales. La Junta Española de Liberación, pacto de unidad forjado en México en 1943 para restablecer la República, publicó el semanario España, hasta que con motivo de su disolución en 1945 fue sustituida por la Gaceta Oficial de la República Española del nuevo gobierno de José Giral (Boned, 1999). Este gobierno puso en marcha el Servicio de Información y Propaganda, que inició su andadura en México, el primer lugar donde se instalaron las instituciones republicanas (Alonso García, 2004; Fernández Alonso, 1996). A instancias de Carlos Esplá y Antoni-Maria Sbert el Servicio se organizó como una empresa privada y se dividió a efectos administrativos en una Agencia de Información - Centro de Información Iberoamericana-, montada para abastecer de noticias a los medios internacionales ${ }^{11}$, y el semanario España Nueva, órgano del gobierno que aspiraba a contribuir en sus páginas a la reinstauración de la República, demostrar la ilegitimidad del régimen de Franco y recordar que su victoria en la guerra supuso un freno para la modernización de España. Sus páginas constituyeron una tribuna para intelectuales, académicos y periodistas como Margarita Nelken, Álvaro de Albornoz o Pedro Bosch i Gimpera. En París, el otro núcleo institucional, se editaba La Nouvelle Espagne, cuyo objetivo era convertirse en el órgano de difusión de las orientaciones y líneas políticas oficiales.

Junto a estos tres canales, el gobierno publicaba folletos con mensajes específicos o declaraciones minis- 
teriales de bajo precio y fácil transporte. Sin embargo, estos medios no pudieron cumplir con las metas propuestas como consecuencia de las dificultades de la distribución - muy compleja ante la dispersión de los lectores $-{ }^{12}$, la falta de personal y los problemas financieros.

Cuando el gobierno de Rodolfo Llopis finalizó en agosto de 1947, el gabinete de Álvaro de Albornoz redujo los gastos y puso el énfasis en la radio. De este modo nació Radio República Española, en el aire por primera vez en abril de 1949 desde Perpiñán. Las emisiones, de una duración aproximada de tres cuartos de hora, se realizaban dos veces por semana y se mantuvieron en antena siete meses, periodo en el que las ondas propagaron el final del régimen franquista justo en el momento en que España salía del aislamiento internacional y se eliminaban las condenas propuestas dos años antes en la Organización de las Naciones Unidas.

En agosto de 1951 el nuevo presidente Félix Gordón Ordás decidió retomar la publicación de los boletines de información y la edición puntual de octavillas, folletos y manifiestos. Asimismo, se planteó como prioridad montar una estación de radio para hacer propaganda hacia el interior de España pero problemas económicos y diplomáticos impidieron que los trámites ante distintos países europeos -Francia y Yugoslavia- y norteafricanos dieran resultados (Alonso García, 2004) ${ }^{13}$. En 1960 el gobierno del general Emilio Herrera ${ }^{14}$ creó una agencia de prensa, Free Spanish Press y editó unos cuadernos mensuales llamados Servicio de Información de la República Española. Sin embargo, al año siguiente se suprimió el Ministerio de Información y con él el definitivo decaimiento de la comunicación republicana. Un arma tan importante como es los medios de comunicación fue menoscabada en tiempos de pleno crecimiento de la radio y la televisión, canales adaptados a una sociedad cambiante y atenta a la información que proporcionaba la moderna tecnología audiovisual.

La prensa republicana en el exilio contó, en general, con la colaboración de lo más brillante de la cultura española, aprovechando la oportunidad de que un gran número de artistas, escritores, poetas, científicos y universitarios de todas las disciplinas se hallaban fuera de España. Muchos se convirtieron en periodistas accidentales, profesionales temporales de los medios, quienes enriquecieron con su sabiduría y su pluma las páginas de la producción impresa en el exilio. Utilizaron todos los géneros periodísticos, pusieron en marcha revistas literarias, como Taller, Romance, Las Españas, Presencia o Comunidad Ibérica y escribieron en las páginas de los diarios mexicanos donde podían ejercer su profesión y ganarse un salario. Los nombres de estas plumas integran un largo repertorio de hombres y mujeres con largos años de experiencia profesional que les permitieron disponer de recursos suficientes para continuar su trabajo en condiciones claramente adversas.

La gran actividad que mostraron, enfrentándose a las dificultades de la disgregación de sus lectores y a la falta de medios económicos para sacar las ediciones, indica la constante preocupación por mantener informados a los exiliados ante la eventual caída del franquismo y la consecuente vuelta a casa, unas circunstancias que se demoraron más años de lo previsto.

\section{LOS CONTENIDOS DE INTERÉS PRIORITARIO: EL FINAL DEL FRANQUISMO}

Prensa y sociedad coincidieron en el espacio y en el tiempo desplegando con intensidad acciones expresivas de intereses comunes como la propaganda a favor de la República o la denuncia de la violencia del franquismo ante la opinión pública, en definitiva, la acusación del Régimen ante la comunidad internacional en su calidad de última reminiscencia de los nazifascismos de entreguerras. Estas críticas continuaron en las décadas de los cincuenta y sesenta, además de la difusión de los movimientos de la oposición antifranquista en el interior y las actividades clandestinas de las fuerzas políticas reorganizadas.

Tanto el gobierno de la República como los partidos y organizaciones republicanas eran conscientes de que la divulgación de sus reivindicaciones a través de los medios de comunicación era una de las vías más efectivas para conseguir el reconocimiento de las potencias occidentales y la actuación contra Franco. El denominador común, como hemos señalado, era la defensa de la legalidad republicana y la denuncia al régimen franquista, aunque todos incorporaban a las páginas de sus cabeceras contenidos reivindicativos propios o propagandísticos destinados a la conquista de su público objetivo: exiliados en general, autoridades internacionales de prestigio o afiliados a partidos. Y es que atendiendo al tipo de publicaciones que mencionamos anteriormente - periodismo político, cultural e institucional-, el papel y las funciones de los órganos de comunicación responden a objetivos diferentes relacionados con su misión fundacional.

Las secciones en las que estaban organizados los medios en el exilio responden a los temas de mayor interés para el colectivo transterrado: información internacional, noticias sobre España, información del partido o institución editores del medio de comunicación y cultura. El análisis cualitativo de los contenidos nos conduce a agruparlos en torno a diferentes temáticas entre las que sobresalen en primer lugar, la represión y las fórmulas practicadas para sobrevivir. En algunos casos, se hacía especial mención a la dura aplicación de estas medidas en las nacionalida- 
des históricas, Cataluña y País Vasco. Se trataba de la expresión pública del dolor como consecuencia de la muerte violenta de familiares y de la persistencia coercitiva. La información sobre cárceles, campos de concentración y el trato dispensado en estos centros formó parte de la agenda mediática exiliada.

En segundo lugar asuntos de política nacional, como reportajes sobre Falange, el carlismo o los monárquicos y su insatisfacción con el Régimen, siendo ésta actitud disidente publicada en la prensa con el propósito de mostrar un síntoma del descontento de estos grupos. Uno de los hechos más vergonzosos para quienes se hallaban fuera de España lo constituyó la política gubernamental de asilo a los acusados en Nüremberg al final de la II Guerra Mundial, medida recogida en grandes titulares de las portadas republicanas como un acontecimiento escandaloso que pretendía llamar la atención sobre la afinidad del franquismo con los antiguos estados nazi-fascistas ${ }^{15}$.

En tercer lugar encontramos noticias relativas a la oposición en el interior. La prensa exiliada reveló la existencia de varios complots para asesinar a Franco y se publicitó la huelga de transportes en Barcelona (1951), primera actuación de la oleada subsiguiente de protestas que caracterizarían la década. Los reportajes sobre las actuaciones guerrilleras fueron también habituales. Con este tipo de noticias se pretendía exteriorizar la fuerza de los opositores tradicionales y el surgimiento de otros descontentos derivados de la pésima situación económica y social.

Otro conjunto de artículos hacen referencia a la economía, con el protagonista indiscutible del estraperlo, el mercado negro, la penuria alimenticia, las anomalías detectadas en el Banco de España, el paradero del capital incautado a los republicanos y las numerosas críticas al intervencionismo estatal. Esta temática se presentaba a modo de indicadores de la pésima marcha de la administración y la corrupción del sistema.

La prensa exiliada prestó una gran atención a la política exterior y la diplomacia por cuanto que el éxito de su gestión estaba vinculado a la supervivencia de la República. Y es que las "maniobras franquistas" estaban dando frutos muy jugosos a la acción exterior del Estado, como la firma de los pactos con los Estados Unidos o el Vaticano. Así en el número de octubre-noviembre de 1953 Izquierda Republicana titulaba: "La independencia que el franquismo proclama: la tierra española hipotecada a Estados Unidos y el espíritu sometido al Vaticano".

Finalmente hemos de mencionar la gran variedad de información cultural que albergaron las publicaciones, desde reseñas literarias a convocatorias de actos científicos y culturales celebrados en las diversas capitales donde residía el colectivo exiliado. En las piezas informativas se hacía especial énfasis en la alta calidad de los participantes de dichos actos con un propósito de exaltar el nivel cultural y profesional de los protagonistas.

Una opinión bastante extendida entre los medios del exilio era el fin próximo de la dictadura. Los disturbios en el interior, la labor de la oposición de dentro y fuera de las fronteras junto a la pésima situación económica, constituían evidencias de que el final del régimen llegaría pronto. Incluso a mitad de los años cincuenta, cuando la España de Franco fue admitida en los organismos internacionales, la España de la República no se dio por vencida, confiada en que un día u otro las potencias democráticas acabarían con la existencia de un gobierno poco apto para la nueva Europa en construcción.

La prensa y la sociedad en el exilio se alimentaron de visiones y percepciones de la realidad bastante sesgadas. Entre 1939 y 1950 la nota dominante fue la esperanza en el triunfo aliado, la caída del franquismo y la lógica vuelta a España. En este tiempo abundaron los contenidos plagados de euforia y de actividad, en plena consonancia con el espíritu de los exiliados, convencidos de la pronta restauración democrática. A partir de 1950 el exilio asistió a la paulatina acogida del franquismo en la sociedad internacional gracias al ingreso en Naciones Unidas y en sus organizaciones dependientes y, sobre todo, contempló con decepción la firma de pactos con la superpotencia del mundo occidental, Estados Unidos. En sus páginas, sin embargo, periodistas y colaboradores seguían insistiendo en la idea de que el final estaba próximo, una opinión afianzada con motivo de la información que llegaba sobre el resurgimiento de la oposición en el interior, las primeras protestas universitarias y las relaciones entre el exilio y la disidencia en el interior que podían contribuir a la forja de una alternativa válida para la sustitución política. El espejismo de estas noticias impedía ver la realidad de una dictadura cada vez más asentada en ese peculiar marco de la Guerra Fría. Los medios y el conjunto del exilio parecían vivir encerrados en la hipótesis de que el mundo daría la razón sin más a la legalidad y a la justicia arrebatada por los militares sublevados del 18 de julio de 1936.

Lo cierto es que la voz de los republicanos, aunque unánime en la denuncia, se presentó de forma fragmentaria, escindida en numerosos grupos casi irreconciliables. Voz de dolor, diluida en un conjunto de individualidades representantes de una cultura de lo imposible, ligada a un ligero quijotismo y aspirante a la implantación de la libertad en esa añorada España. No podía ser de otro modo ante tantas agresiones físicas y psicológicas en una coyuntura en la que apenas hubo sosiego para un análisis realista en el entorno difícil de Francia o en el teórico paraíso de México, 
donde tenían que dedicarse a problemas de su integración en el mercado laboral.

Sociedad y prensa no se apercibieron de que el franquismo estaba asegurado y que contaba con apoyo entre la población, conseguido a través del miedo y su aliado, el silencio, o simplemente ganado con el consenso de las clases sociales pro-franquistas. Tampoco reconocieron o no fueron capaces de reconocer que el Régimen estaba sustentado por la sociedad internacional, bien por acción - caso de las dictaduras iberoamericanas, de Estados Unidos, del Vaticano, de algunos países árabes y de otras dictaduras asiáticas y africanas-, bien por omisión, como consecuencia del principio de la no ingerencia en asuntos internos de los Estados. La alimentación recíproca de la ilusión de la caída del franquismo, junto al problema central de la fragmentación política interna, fue tremendamente perjudicial para todos porque les impidió disponer de un interlocutor ante las democracias y planificar una estrategia que pudiera ser ofertada ante los foros internacionales como la alternativa democrática al franquismo. Les faltó autocrítica y un análisis profundo de la realidad española; tampoco hubo éxito en los llamamientos a la unidad republicana. A partir, pues, de 1950, apenas se pusieron en marcha nuevas iniciativas y muchos medios de comunicación tuvieron que cerrar sus redacciones, a excepción de las cabeceras de la prensa política, la más duradera de toda la tipología informativa como consecuencia de su vinculación a los partidos y sindicatos de la oposición.
1. Gran Bretaña recibió un goteo de exiliados desde 1939. Muchos trabajaron en la BBC para las emisiones en español de esta cadena como Luis Araquistain, Segismundo Casado, José Castillejo, Arturo Barea o Luis Portillo, quien además de trabajar como traductor, mantuvo un programa llamado Radio Gaceta hasta fines de la década de los cincuenta.

2. Se hacían primero a mano y luego con máquinas de escribir. Uno de ellos era El Bulo, confeccionado a modo de boletín oral. En la II Guerra Mundial en el campo de Gurs y en otros de Francia circulaban hojas como La Voz de España y la Voz de los Españoles. En el buque Sinaia, primera expedición de españoles a México, se improvisaron recursos materiales y humanos para recoger diariamente las incidencias del viaje y aprovechar la oportunidad de realizar entrevistas, semblanzas e informaciones sobre la situación mundial. Las hojas multicopiadas Sinaia son, junto a las de El Bulo, las primeras muestras del periodismo en el exilio.

3. Catálogo de publicaciones en Archivo de la República en el Exilio, Fondo París (en adelante ARE-FP).

4. Disponible en la Fundación Pablo Iglesias (FPI) y digitalizado en http://www.fpabloiglesias.es/fundacionpabloiglesias/ fpi/hemeroteca.jsp? (acceso el 24 de mayo de 2010).
5. Los miembros del PCE reclamaban a la dirección del partido el envío de estos medios de comunicación, nexos importantes entre ellos y soportes informativos de gran valor para los residentes en estas capitales del Telón de Acero. Archivo Partido Comunista de España (en adelante APCE). Emigración Política. Rumania, 96/5.1.

6. Emigración política. Polonia. 96/4. APCE.

7. Emigración Política. Rumania, 96/5.1. APCE.

8. Quería, además, ser un instrumento de comunicación entre los militantes republicanos repartidos por todo el mundo. Algunos de los redactores y colaboradores eran Carlos Esplá, Juan Bautista Climent, Álvaro de Albornoz, José Giral, Julio Just, Marcelino Domingo, Claudio Sánchez Albornoz. Véase Archivo Carlos Esplá, dirección web: http://www.cervantesvirtual.com/portal/ACE/ (acceso el 4 de junio 2010).

9. El Ateneo se constituyó como un centro cultural dedicado al estudio de los problemas de España y del republicanismo, y tenía como máxima prioridad la unión de todos los republicanos respetando la identidad de los partidos de origen. Era una asociación fundada por antiguos militantes de Izquierda Republicana disidentes de ARDE encabezada por Carlos Esplá.
10. El primer número salió en 1939, y aunque con cambios en la periodicidad, logró prolongarse hasta 1976. Personajes de la talla intelectual de Albert Einstein, Pablo Casals, Rubia Barcia o Ramón J. Sender, constituían las asiduas firmas de sus páginas. Su contenido se estructuraba básicamente en torno a dos partes, por un lado la actualidad del momento referida a España y la situación del exilio, y por otro, artículos de opinión y ensayos de exiliados que escribían respecto de estas noticias. La heterogeneidad de sus firmas confirma la diversa opinión de los exiliados. Véase en ARE-FP.

11. Trabajaron con agencias internacionales y gestionaron distintos contactos con redactores de medios de comunicación de Europa y América tanto para convencerles de que informaran en sus diarios contra el régimen franquista como para que utilizaran la información que ellos proporcionaban. El fichero de receptores se lo habían facilitado partidos, ateneos, centros regionales, etc. ARE-FP.

12. La distribución, especialmente rudimentaria, era la causa de que la recepción fuera muy irregular, cuando apenas interesaba ya la información que contenía porque era conocida a través de otros medios. Se hacía a través de un corresponsal al que se remitía un número de ejemplares y éste corresponsal era el encargado de venderlo entre las colonias de españoles. 
13. En 1959 Gordón Ordás consiguió que Venezuela cediera el permiso necesario para el funcionamiento de Radio Libertad, con emisiones de sólo media hora. La escasez de recursos tecnológicos y humanos impedía la preparación de una programación más amplia y como consecuencia de ello el impacto propagandístico e informativo fue mínimo, entre otras razones porque el alcance de sus ondas apenas cubría el continente americano.

14. El general Emilio Herrera fue muy activo mediáticamente hablando y participó

\section{BIBLIOGRAFÍA}

Abellán, J. L. (1982). De la guerra civil al exilio republicano (1936-1977). Madrid: Mezquita.

Alonso García, M. R. (2004). Historia, Diplomacia y propaganda de las instituciones de la República Española en el exilio (1945-1962). Madrid: Fundación Universitaria Española.

Alted, A. (2006). El exilio republicano en México. Boletín de la Institución Libre de Enseñanza, № 61, 9-14.

Angosto, P. L. (2001). Sueño y pesadilla de republicanismo español. Carlos Esplá: una biografía. Madrid: Biblioteca Nueva.

Arasa, D. (1995). Exiliados y enfrentados: los españoles en Inglaterra de 1936 a 1945. Barcelona: Ediciones de la Tempestad.

Atienza, E. (2010). Ciencia en las ondas. Crónicas científicas de Emilio Herrera. Madrid: Fundación Aena.

Bahamonde, A. y Sánchez Illán, J. C. (eds.) (2010). Una república de papel: L'Espagne Républicaine (1945-1949). Madrid: Fondo de Cultura Económica.

Bahamonde, A. y Sánchez Illán, J. C. (2008). Una voz errante del periodismo españo en el exilio: 'L'Espagne Républicaine' (1945-1949). Textual \& Visual Media: revista de la Sociedad Española de Periodística, $\mathrm{n}$ ㅇ, 1, pp. 71-85.

Boned, A. (1999). Prensa y exilio: el semanario España. Cuadernos Republicanos, no $38,27-38$. durante 1950-51 en Radio París con un espacio sobre divulgación científica. Al respecto, Atienza, Emilio, Ciencia en las ondas. Crónicas científicas de Emilio Herrera, Madrid, Fundación Aena, 2010.

15. El 16 de julio de 1948 España Libre daba la escalofriante cifra de 70.000 nazis refugiados en España en 1948. España Nueva decía en su ejemplar de 30 de marzo de 1946 que el país se había convertido en un centro de información nazi y Barcelona en la sede industrial y financiera nacional a base de una aportación económica de origen nazi. Según estos medios, los alemanes derrotados se escondían en conventos, cambiaban de nombres, pasaban a ser ayudantes de las fuerzas de seguridad nacionales, etc. ARE- FP. La historiografía actual ha demostrado que estas informaciones no eran una invención, Collado, C., (2005): España, refugio nazi, Madrid, Temas de Hoy; o J.M. de Irujo, (2003): La lista negra. Los espías nazis protegidos por Franco y la Iglesia, Madrid, Aguilar.
Cabeza Sánchez-Albornoz, S. (1997). Historia política de la Segunda República en el exilio. Madrid: Fundación Universitaria Española.

Carcedo, D. (2006). Neruda y el barco de la esperanza. Madrid: Temas de Hoy.

Díez, L. (2010). El exilio periodístico español. México, de 1939 al fin de la esperanza. Cádiz: Quórum editores.

Domínguez Prats, P. (1998). Mercedes Pinto: una exiliada canaria en Hispanoamérica. VIII Coloquio de Historia CanariasAmérica, Las Palmas de Gran Canaria: Ediciones del Cabildo de Gran Canaria, pp. 311-326

Egido, A. (coord.) (2006). Memoria de la Segunda República: mito y realidad. Madrid: Biblioteca Nueva y Centro de Investigación y Estudios Republicanos.

Egido, A. y Eiroa, M. (2005). Los grandes olvidados. Los republicanos de izquierda en el exilio. Madrid: CIERE.

Eiroa, M. (2011). Sobrevivir en el socialismo. Organización y medios de comunicación de los exiliados comunistas en las democracias populares. Historia Social, no 69, pp. 71-89.

Fernández Alonso, I. (1996). Aproximación a la política propagandística del exilio. Cuadernos Republicanos, no 25, 33-42.

Forment, A. (2000). José Martínez: la epopeya de Ruedo Ibérico. Barcelona: Anagrama.
González Neira, A. (2002). La prensa del exilio español. En C. Almuiña y E. Sotillos (coord.), Del Periódico a la Sociedad de la Información. Madrid: España Nuevo Milenio, pp. 241-251.

Gutiérrez Palacio, J. (coord.) (2009). De Azorín a Umbral. Un siglo de periodismo universal. La Coruña: Netbiblo.

Lemús, E. (coord.) (2002). Los exilios en la España contemporánea. Ayer, no 47, Madrid, Marcial Pons y Asociación de Historia Contemporánea.

Mendezona, R. (1995). La Pirenaica y otros episodios. Madrid: Editorial Literarios.

Millán Trujillo, M. J. (1998). Radio España Independiente: información y propaganda desde el exilio. Cuadernos Republicanos, nㅇ 34, 47-69.

Naranjo Orovio, C. (coord.) (2009). Los destinos inciertos: El exilio republicano español en América Latina. Arbor, no 735, Vol. 185, Madrid, CSIC.

Ordaz, M. A. (1990). El exilio español en Estados Unidos. Los intelectuales de España Libre. En J. Tusell, A. Alted y A. Mateos (coord.). La oposición al Régimen de Franco. Actas de Congreso Internacional. Madrid: UNED. Vol II. 73- 83.

Piedrafita, F. (1996). Fondo Hemerográfico del Archivo de la Il República Española en el Exilio. Madrid: Fundación Universitaria Española.

Sánchez Illán, J. C. (2005). El periodismo republicano en el exilio: entre Francia y México (1939-1975). En A. Miquel 
y otros (comp.): Imágenes cruzadas. México y España, siglos XIX y XX. México: Universidad Autónoma.

Sánchez Illán, J. C. (dir.) (2011). Diccionario biográfico del exilio español de 1939. Los periodistas. Madrid: Fondo de Cultura Económica.

Sánchez Vázquez, A. (ed.) (1989). Sinaia. Diario de la primera expedición de re- publicanos españoles a México, edición facsimilar. México: UNAM.

Surroca i Tallafero, R. (2004). Premsa catalana de l'exili i l'emigració, Barcelona, Generalitat de Cataluña.

Schwarzstein, D. (2001). Entre Franco y Perón: memoria e identidad del exilio republicano español en Argentina. Barcelona: Crítica.
Zaragoza, L. (2007). La única emisora española sin censura de Franco: una aproximación a la Pirenaica. En M. Bueno y otros (coords.), Historia del PCE. I Congreso, 1920-1977, Vol II. FIM, Madrid, pp. 569-581.

Zaragoza, L. (2008). Radio Pirenaica. La voz de la esperanza antifranquista. Madrid: Marcial Pons. 